\section{OPAC 2.0: \\ análise das propriedades, serviços e recursos da Web 2.0}

Rafael Gonçalves Dias" Célia da Consolação Dias ${ }^{* *}$

RESUMO: Nos últimos anos, Catálogos Online de Acesso Público (OPAC)
vêm passando por transformações devido ao desenvolvimento
tecnológico e por uma susposta exigência de usuários habituados
com serviços mais interativos proporcionados pela Web 2.0. Na
tentativa de atender aos anseios dos usuários observa-se em alguns
estudos a proposição do desenvolvimento do OPAC 2.0 . Neste
caso, obverva-se que se o OPAC 2.0 é aquele que está alinhando ao
conceito Web 2.0 e faz uso seus mecanismos, considera-se oportuno
investigar através de um estudo exploratório as proriedades da Web
2.0 , como os princípios, serviços e recursos que dão origem ao
proposto OPAC 2.0 . Este estudo visa, portanto, proporcionar maior
clareza quanto as propriedades da Web 2.0 em relação ao que se
espera de um OPAC 2.0 . Para esta tarefa recorreu-se a literatura
especializada para estabelecer pontos de ligação entre Web 2.0 e
Ciência da Informação e identificar métodos de avaliar, classificar
ou identificar elementos da Web 2.0 em serviços de informação.
O resultado da pesquisa indica que a literatura especializada ainda
carece de fundamentação teórica e procedimentos técnicos para
avaliar OPAC que venham a reivindicar o "selo" 2.0 . Concluí-se
que sem as devidas reflexões e esclarecimento, corre-se o risco de
desenvolver serviços desalinhados às reais necessidades dos usuários.

Palavras-chave: OPAC 2.0. Web 2.0. Recursos 2.0. Catálogos.
* Mestrando em Ciência da Informação pelo Programa de pós-graduação em Gestão \& Organização do Conhecimento da Escola de Ciência da Informação da Universidade Federal de Minas Gerais, Brasil. Graduado em Biblioteconomia pela Universidade Federal de Minas Gerais, Brasil.

E-mail: rafaeldiasufmg@hotmail.com.

** Doutora em Ciência da Informação pela Universidade Federal de Minas Gerais, Brasil. Docente permanente no Programa de Pós-Graduação Gestão \& Organização do Conhecimento da Universidade Federal de Minas Gerais, Brasil.

E-mail: celiadias@gmail.com.

\section{INTRODUÇÃO}

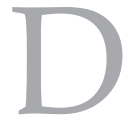
iante do contexto tecnológico e interativo da Web 2.0 tem se suposto que usuários de serviços de informação familiarizados com esse novo ambiente poderiam esperar por catálogos bibliográficos igualmente inseridos neste conceito. Autores como Lima (2011), Ribeiro e Silva (2015), Castro e Moreno (2013) e Tam, Cox e Bussey (2009) sustentam a ideia da existência de um novo perfil de usuário, como seria o caso dos "nativos digitais" aqueles usuários que desde muito jovens tiveram contato com tecnologias, dispositivos, objetos digitais e com a web, e mesmos aqueles não nativos que se adaptaram a esse novo ambiente. O argumento, recorrente, costuma ser referente à discrepância percebida entre catálogos de bibliotecas com serviços típicos de Web 2.0, como redes sociais, buscadores populares como Google e site de lojas virtuais como Amazon. Neste cenário, acredita-se que usuários poderiam se sentir desestimulados com serviços supostamente não tão desenvolvidos no quesito Web 2.0, ou até mesmo, em alguns casos, sentirem dificuldades no uso dos catálogos por considerá-los obsoletos.

O aperfeiçoamento dos catálogos enquanto produto e serviço de informação se dá através de pesquisas realizadas pela Biblioteconomia e Ciência da Informação (CI) aliada ao 
desenvolvimento tecnológico computacional, como no caso da disponibilização do serviço via web. Fato observado no desenvolvimento dos catálogos automatizados conhecidos como Online Public Access Catalog - OPAC (catálogo online de acesso público). Ainda hoje o uso de novos recursos de Tecnologias da Informação e Comunicação (TIC) tem contribuído para o aperfeiçoamento de serviços de bibliotecas como nos catálogos eletrônicos. (LIMA, 2011).

Ao passo que os OPAC se desenvolveram e utilizam recursos da web, deve-se considerar, obviamente, que a própria web evoluiu para o que hoje é conhecida como Web 2.0 ou Web Social. A Web 2.0 é geralmente conhecida com a segunda geração da grande rede em que os serviços estão associados a um maior grau de interação entre administradores e usuários. Daí a ligação que se observa entre OPAC e Web 2.0, ou seja, o OPAC 2.0, como proposto por Lima (2011), Ribeiro e Silva (2015). Conforme Johnson e Cravent (2010), a partir de 2004 com o surgimento da Web 2.0 houve uma rápida evolução das tecnologias, algumas delas aplicadas a catálogos, que possibilitaram aos usuários a criação de conteúdo, comentar sobre um item, ter de perfil rastreado para fornecer recomendações.

Todavia, em uma primeira aproximação ao tema proposto, verificou-se a falta de clareza em alguns pontos específicos da Web 2.0, como os princípios, tecnologias, serviços, recursos e as relações com a $\mathrm{CI}$, fato que dificulta o entendimento do que seja realmente necessário para um OPAC ser classificado como 2.0.

Diante do exposto, este artigo tem como objetivo identificar os elementos e propriedades da Web 2.0 e do OPAC 2.0 a fim de esclarecer de fato o que é necessário para um OPAC ser classificado como tal.

\section{METODOLOGIA}

A pesquisa neste estudo é de caráter exploratório, visa proporcionar maior clareza em relação ao tema. O estudo foi desenvolvido através de pesquisa bibliográfica realizada em função de projeto de pesquisa de mestrado. $\mathrm{O}$ estudo exploratório foi desenvolvido atráves de uma pesquisa bibliográfica realizada em literatura técnico-científica especializada em tecnologia e CI com intuito de identificar pesquisas tratando serviços e recursos alinhados ao conceito Web 2.0. A intenção inicial da pesquisa foi verificar o grau de alinhamento de catálogos bibliográficos aos pressupostos da Web 2.0, uma vez que avaliou a necessidade de saber em que nível que OPAC de bibliotecas estão se valendo dos benefício desse ambiente para tornar seu serviço mais moderno e mais interessante para os usuários.

Percorrendo o caminho proposto através dos objetivos da pesquisa de mestrado, a revisão de literatura permitiu conhecer as propriedades da Web 2.0, o conceito fundamental deste ambiente que está diretamente alinhado aos princípios da Web 2.0 propostos por O'Reilly (2005) e ainda revelou uma série de questões importantes. Uma dessas questões trata justamente do tema central deste artigo que são o funcionamento e comportamento de serviços e recursos 2.0, uma vez que verificou-se propostas de modernizar catálogos de bibliotecas, enquanto serviço, através da implementação dessas tecnologias da Web 2.0.

A partir da revisão de literatura, como em Anderson (2007) e O'Reilly (2005) foi possível identificar algumas pesquisas que se aproximaram do tema deste artigo mencionando vários serviços e recursos classificados como “2.0".

$\mathrm{Na}$ tentativa de aproximar a Web 2.0 da CI foram pesquisados várias propostas de aperfeiçoamento de serviços de serviços especializados de informação, como o OPAC 2.0, como nas pesquisas de Silva (2013), Lima (2011) e Tam, Cox e Bussey (2009).

\section{A WEB 2.0}

Entre consenso e dissenso é atribuída a Web 2.0 uma nova fase ou geração da web, em que se percebeu o desenvolvimento de um ambiente que alterou, ou pelo menos ampliou, as relações entre sistemas e usuários que passaram a acontecer em via de mão dupla. Na revisão de literatura de sobre a Web 2.0, observou-se que as definições sobre esse ambiente nem sempre são claras, por esta razão considera-se importante discutir o conceito que está quase sempre associado à interatividade.

Para Aretio (2007) as características principais dos sistemas Web 2.0 são 
interatividade, aprendizagem colaborativa, multidirecionalidade e liberdade de edição e disseminação. Conforme Coelho, Ishitani e Nelson (2012) a Web 2.0 não é uma nova tecnologia, mas uma maneira mais participativa de utilizar e ver a rede como uma plataforma. Anderson (2007, p. 53) ao se referir aos pontos fundamentais que se deve refletir sobre a Web 2.0, alerta que a Web 2.0 é mais do que um conjunto de "ideias legais", novas tecnologias e serviços. Para Anderson (2007) há por trás da Web 2.0 grandes ideias que estão mudando as formas de interação entre as pessoas. Para Funk (2007), não é tarefa fácil compreender a Web 2.0 e, muitas vezes, este termo pode ser utilizado de maneira imprecisa, com diversas definições, todavia, segundo o autor, para facilitar a compreensão pode-se observar algumas características que são mais evidentes, como a possibilidade de interação e participação dos usuários.

\begin{abstract}
A Web 2.0 descreve a World Wide Web atualizada, melhorada e modernizada que estamos usando hoje. É um termo usado vagamente para se aplicar a tudo, desde a explosão de sites de redes sociais como o MySpace e o YouTube, até os ricos e interativos aplicativos de software que estão sendo atendidos online e até as linguagens de programação específicas e ferramentas tecnológicas que tornam a "nova" web possível. Web 2.0 é uma transformação social que colocou mais interatividade e controle de conteúdo nas mãos de usuários regulares, não apenas grandes proprietários de sites. (FUNK, 2007, p. I, tradução nossa).
\end{abstract}

Outra característica relevante a se considerar, dentro da definição apresentada por Funk (2007), é sobre o conjunto de elementos que compõe a Web 2.0, como tecnologias, softwares, serviços e linguagens de programação. Esse conjunto de elementos mencionados por Funk (2007) indica que a Web 2.0 é composta por diversos mecanismos, além de recursos.

Tim O'Reilly, considerado por vários pesquisadores o responsável pela popularização do termo "Web 2.0" sintetiza o conceito de Web 2.0 da seguinte forma:

A Web 2.0 é a revolução do negócio na indústria de computadores causada pelo movimento para a internet como plataforma, e uma tentativa de entender as regras para o sucesso nessa nova plataforma. $\bigcirc$ principal entre essas regras é o seguinte: crie aplicativos que aproveitem os efeitos da rede para melhorar cada vez mais como pessoas as usam. (É o que eu chamo em outro lugar "aproveitando a inteligência coletiva"). (O’REILLY, 2006, online, tradução nossa).

O'Reilly (2005) alega que o termo “Web 2.0" já possuía um grande número de registros de citações na Internet, porém muitas vezes em desacordo com o seu real significados. O termo Web 2.0 muitas vezes era usado apenas como estratégia de marketing, pois alguns serviços recebiam esse rótulo sem que realmente apresentassem as características correspondentes à Web 2.0. Um dos resultados da conferência mencionada foi a publicação de um artigo que buscou dar maiores esclarecimentos sobre esse novo ambiente. De acordo com a referida publicação, a Web 2.0 seria um ambiente em que os serviços ali disponibilizados estariam associados a uma série de sete princípios. Os sete princípios, em maior ou menor grau, deveriam ser observados nos serviços conforme explicado por O'Reilly (2005, p. 2): “pode-se visualizar a Web 2.0 como um conjunto de princípios e práticas que interligam um verdadeiro sistema solar de sites que demonstram alguns ou todos esses princípios e que estão a distâncias variadas do centro". Diante dessa informação é oportuno ressaltar que, para O'Reilly (2005), os serviços Web 2.0 não precisam necessariamente atender a todos os princípios. Observou-se, entretanto, que não há muita clareza em relação à definição sobre a quantidade mínima de princípios atendidos e o grau de proximidade do "centro" da Web 2.0. Em termos mais práticos para o presente artigo, seria possível considerar que não fosse necessário, por exemplo, que um suposto OPAC 2.0 possuísse os sete princípios para ser classificado como tal. Como O'Reilly não apresentou critérios bem definidos para dar o "selo" Web 2.0 aos serviços analisados, infere-se que seja possível realizar análises com critérios variados desde que pelo menos seja observada a presença dos princípios sugeridos.

Por ora, é possível analisar e esclarecer quais são os sete princípios, pois há indícios que estes podem ser utilizados como norte para classificar qualquer tipo de serviço 2.0, inclusive na análise de OPAC 2.0 que é o foco deste artigo. 


\section{I Os sete princípios da WEB 2.0}

A seguir cada um dos sete princípios será apresentado de forma breve:

\section{I) A Web como plataforma}

Para O'Reilly (2005), a Web como plataforma reflete a ideia de que as aplicações funcionam através da Internet, se baseia na ideia de serviço e não de software. Altera o modelo tradicional de oferecimento de software instalado no computador, ou que se comunicava apenas com servidor próprio, para um modelo de serviços conectados e operando através da web.

De acordo com Silva (2013, p. 82) a web evoluiu de um imenso repositório de documentos e informações para a $W e b 2.0$ que:

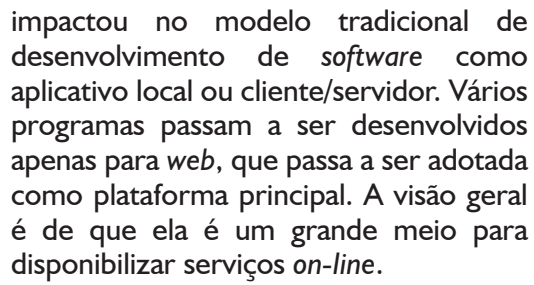
aplicativo local ou cliente/servidor. Vários programas passam a ser desenvolvidos apenas para web, que passa a ser adotada como plataforma principal. A visão geral é de que ela é um grande meio para disponibilizar serviços on-line.

Por isso, entende-se que, aos moldes da Web 2.0, basta que os serviços estejam disponíveis via web para atender a este princípio.

Lima (2011) tem uma visão mais prática do comportamento deste princípio, segundo a autora "os usuários comunicam entre si através de texto, imagem, voz, vídeo ou através de uma combinação entre suportes" (LIMA, 2011, p. 6, tradução nossa).

\section{II) Tira proveito da inteligência coletiva}

O'Reilly (2005) apresenta a inteligência coletiva como um dos princípios da Web 2.0 através de exemplos de usos práticos, tais como apontado a seguir:

- Amazon; eBay - São basicamente catálogos comerciais que exploraram a inteligência coletiva quando permitem que seus clientes/usuários contribuam com avaliações.

- Wikipedia - Uma enciclopédia online construída de forma colaborativa. Os verbetes são escritos pelos usuários de forma descentralizada.
- Blogs - São como diários públicos e virtuais em que o proprietário, normalmente, utiliza para disponibilizar informações de forma independente.

Braga (2009) e Santos (2011) observaram a complexidade da inteligência coletiva ao considerar seu papel gerador de riqueza nas interações sociais, diferente das riquezas particulares como as competências, habilidades e valores dos indivíduos.

Bembem e Costa (2013) identificaram e analisaram a inteligência coletiva no campo de estudos da CI se baseando na obra de Pierre Lévy. Para Lévy (2003, p. 28) a inteligência coletiva:

É uma inteligência distribuída por toda parte, constantemente valorizada, coordenada em tempo real, levando a uma efetiva mobilização de competências. Adicionar a nossa definição desta ideia essencial do fundamento e meta da inteligência coletiva é o reconhecimento mútuo e enriquecimento das pessoas, e não o culto de comunidades fetichizadas ou hipostasiada.

Para Bembem e Costa (2013) as questões referentes ao trabalho colaborativo são da competência da $\mathrm{CI}$, pois compreendem um de seus principais objetivos: o estudo dos fluxos da informação desde sua criação até a sua utilização. Em termos práticos para Bembem e Costa (2013, p. 141) a questão da inteligência coletiva pode ser visualizada na Web 2.0 através do uso de tags:

\begin{abstract}
Nos ambientes colaborativos da Web 2.0, é possível ao próprio usuário colaborador fazer a representação de informações, por exemplo, pela atribuição de tags aos conteúdos. Além disso, nesses ambientes a comunicação ocorre de todos para todos, a informação torna-se compartilhada e o armazenamento de informações ocorre em estoques de informação cada vez mais descentralizados.
\end{abstract}

Silva (2013) destaca o uso da inteligência coletiva a partir da experiência de alguns sites na produção coletiva de informações para a melhoria da qualidade dos serviços, neste sentido o autor afirma que: 
[...] na Web 2.0, muitos sites estimulam os usuários a produzir mais informações coletivamente e, quanto mais e em maior escala isso for realizado, mais valor e impacto o site tem. Mais do que apenas produzir informação, um dos objetivos principais desses sites é utilizar da colaboração de cada usuário para a melhoria contínua da qualidade do serviço, o que foi chamado de uso da inteligência coletiva. (SILVA, 20I3, p. 82).

\section{III) Dados são o próximo Intel Inside}

O'Reilly (2005) não detalha o que significa "Intel Inside", o que se sabe é que este termo era utilizado como propaganda dos processadores (hardware) produzidos pela empresa Intel. Se para O'Reilly (2005) dados são o próximo Intel Inside leva-se a crer que para ele na Web 2.0 o dado é o elemento mais importante e não mais a capacidade de processamento. Nesse quesito um exemplo trazido por O'Reilly (2005, p. 17) foi o caso da Amazon que "seu banco de dados original veio da R.R. Bowker que fornece os registros ISBN", e que a empresa apenas trabalhou na "melhoria dos dados, acrescentando informações fornecidas pelas editoras tais como imagens da capa, sumário, índice e acesso a trechos dos livros. E, o que foi mais importante, "ela engajou seus usuários a fazerem comentários sobre os dados".

Para Silva (2013, p. 83) este princípio aponta para o dado como o elemento mais importante:

De uma maneira geral, quanto mais informações forem agregadas, produzidas por especialistas ou usuários, mais valor e importância o site tem. $O$ dado chega a ser superior à tecnologia empregada na construção da mesma, já que isto pode ser copiado.

De acordo com Lina (2011) este princípio pressupõe uma eficaz gestão de dados, e assim pode-se ter como exemplo a criação e manutenção de bases dados especializadas.

IV) O fim do ciclo de lançamentos de software

Trata-se basicamente da mudança da noção de software como produto para serviço, os quais precisam ser constantemente atualizados.
"A mudança do software como produto para software como serviço é tão fundamental que o software deixará de funcionar a não ser que receba manutenção diária." (O'REILLY, 2005, p. 4, tradução nossa).

Para Silva (2013, p. 83), "é comum dizer que essas aplicações acessadas pela web são um 'beta perpétuo», que nunca finalizam seu desenvolvimento ou o ciclo de lançamento do produto".

V) Modelos leves de programação

Está associado à programação e desenvolvimento de software da forma mais simples possível. Pressupõe-se que quando os serviços são desenvolvidos em modelos de programação simples, torna-se mais fácil sua distribuição e utilização, ao contrário de modelos mais complexos que, em alguns casos, poucos desenvolvedores terão a capacidade de manuseio. Para O'Reilly (2005, p. 22) o Google Maps é um exemplo por ter sido desenvolvido uma interface simples, do tipo AJAX (Javascript e XML).

VI) Software em mais de um dispositivo.

Como o próprio título indica, uma das características da Web 2.0 consiste em serviços acessíveis por vários dispositivos, ao contrário do que seria de costume na Web 1.0 em que o acesso ao serviço era somente através de computadores de mesa (desktop).

VII) Experiência rica do usuário

O'Reilly (2005) menciona que, pelo menos desde 1992, a web já usava aplicativos web ou "applets", que nada mais são que aplicativos que são executados via navegadores (browser). Já no contexto da Web 2.0 esses aplicativos web ganham mais importância quando passam a oferecer serviços mais sofisticados. Um exemplo simples e claro citado por O'Reilly (2005) são os editores de texto Web 2.0 que hoje são tão desenvolvidos que suportam formatação similar às encontras em versões instaladas nos computadores.

Conforme Lima (2011, p. 6, tradução nossa) de maneira simples este princípio pressupõe "interfaces amigáveis, simples e com múltiplas funcionalidades". 


\subsection{Serviços e recursos $\mathbf{2 . 0}$}

A Web 2.0 é sempre lembrada pelos recursos e serviços encontrados em vários tipos de sites, sobretudo aqueles que oferecem ferramentas que estimulam os usuários a interagirem com os produtos e serviços disponíveis na Internet. É bem comum associar a Web 2.0 às redes sociais, blogs, mecanismo de comentar, curtir e compartilhar e sistemas de tags (etiquetagem). Diante dessa associação de serviços e recursos também se observa um problema relevante quando se menciona esses mecanismos da Web 2.0: a delimitação do que seria um serviço ou um recurso (e outras diversas expressões empregadas). Em uma leitura mais atenta na literatura especializada observa-se a existência de vários termos e expressões que torna confusa a tarefa de identificar os mecanismos que compõe a Web 2.0. Nem mesmo a revisão de literatura permitiu obter maiores esclarecimentos quanto ao significado de cada termo. Por isso é oportuno deixar claro qual entendimento que se dá a duas expressões muito frequente neste artigo: serviço e recurso. Considerou-se serviço como algo mais amplo e recurso como algo mais específico. Enquanto que um serviço seria representado por um site, os recursos são os mecanismos que oferecem determinadas funcionalidades. Por exemplo, o Facebook é um serviço 2.0 de rede social que possui alguns recursos 2.0: curtir, compartilhar, marcar, entre outros, como ilustrado a seguir:

Figura 1: Serviços e recursos 2.0

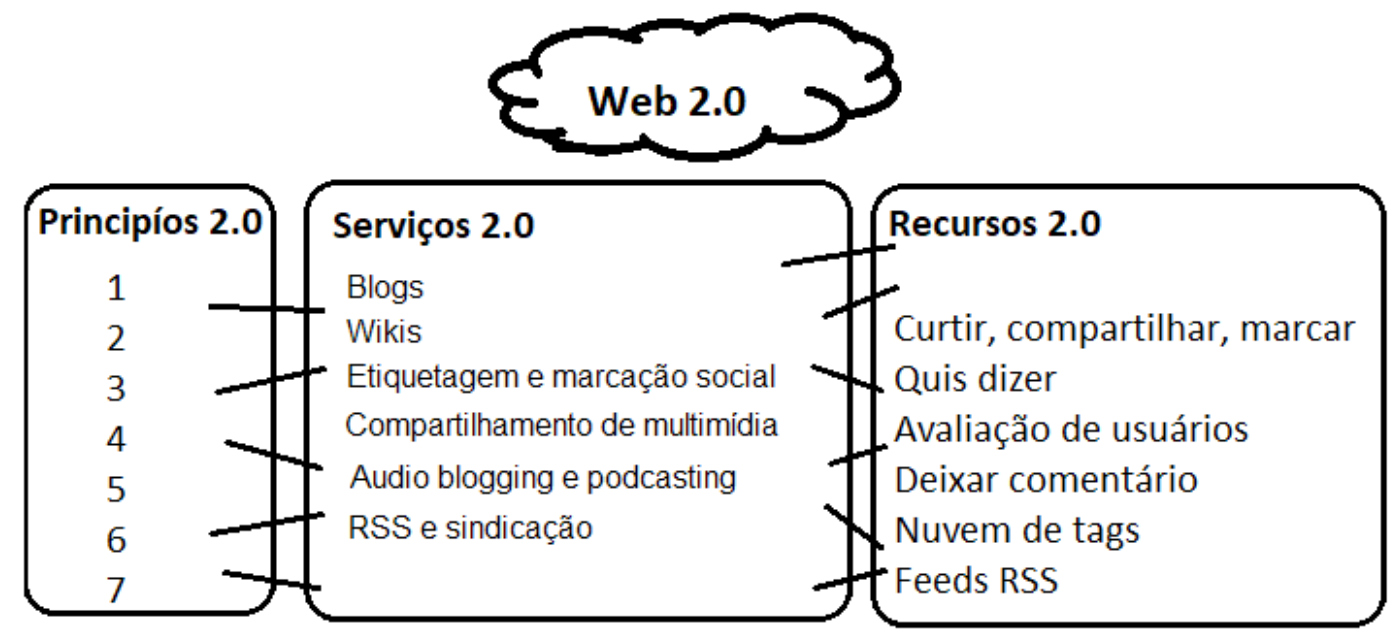

Fonte: Elaborado pelos autores

Conforme a figura 1, a Web 2.0 possui vários elementos que estão interligados. Os princípios estão associados aos serviços 2.0 que por sua vez utilizam recursos 2.0. Podese compreender também que recursos são os mecanismos mais específicos pelos quais os serviços 2.0 disponibilizam algumas funcionalidades.

De acordo com Anderson (2007), que pesquisou os impactos da Web 2.0 no setor da educação superior no Reino Unido, as tecnologias Web 2.0 concentram-se em aplicações/ serviços comuns, como blogs, wikis, serviços de compartilhamento de multimídia, distribuição de conteúdo, podcasting e serviços de tagging de conteúdo. Esses tipos de serviços também foram citados por Hossain e Aydin (2011) e Liesegang (2007) que avaliaram a Web 2.0 como uma nova tendência na tecnologia de comunicação interativa e interoperável. Tais serviços são, para Anderson (2007), manifestações iniciais da proposta original da Web 2.0. Além desses serviços típicos de Web 2.0 citados por Anderson (2007), o autor apresentou uma lista auxiliar para classificar novos serviços. As novas categorias estão representadas no quadro 1 : 
Quadro 1: Novos serviços Web 2.0

\begin{tabular}{|c|c|c|}
\hline Categorização & Breve explicação para grandes ideias da Web 2.0 & Exemplos \\
\hline Redes sociais & $\begin{array}{l}\text { Sites de redes sociais e profissionais que facilitam conhecer } \\
\text { pessoas e compartilhar conteúdos - aproveita o poder da } \\
\text { multidão. }\end{array}$ & $\frac{\text { Linkedin }}{\frac{\text { Myspace }}{\text { facebook }}}$ \\
\hline $\begin{array}{l}\text { Serviços } \\
\text { agregação }\end{array}$ & $\begin{array}{l}\text { Reúna fontes através da web e publique em um só lugar. Inclui } \\
\text { notícias e agregadores de feed RSS. } \\
\text { Recolhe e agrega dados do usuário, atenção do usuário (o que } \\
\text { você olha) e intenções. }\end{array}$ & $\begin{array}{l}\frac{\text { Techmeme }}{\text { Blogbridge }} \\
\underline{\text { Suprglu }} \\
\text { Netvibes } \\
\underline{\text { Attentiontrust }} \\
\text { Digg }\end{array}$ \\
\hline Data 'mash-ups' & $\begin{array}{l}\text { Serviços web que reúnem dados de diferentes fontes para criar } \\
\text { um novo serviço (ou seja, agregação e recombinação). }\end{array}$ & $\begin{array}{l}\text { Housingmaps } \\
\underline{\text { iSpecies }}\end{array}$ \\
\hline $\begin{array}{l}\text { Acompanhamento } \\
\text { e filtragem de } \\
\text { conteúdo }\end{array}$ & $\begin{array}{l}\text { Serviços que acompanham, filtram, analisam e permitem a } \\
\text { busca de quantidades crescentes de conteúdo da Web } 2.0 \text { de } \\
\text { blogs, serviços de compartilhamento multimídia, etc. }\end{array}$ & $\frac{\text { Synacor }}{\text { Digg }}$ \\
\hline Colaboração & $\begin{array}{l}\text { Trabalhos de referência colaborativa (como a Wikipédia) que } \\
\text { são criados usando softwares semelhantes aos wikis. } \\
\text { Ferramentas colaborativas, de projeto baseado na web e de } \\
\text { produtividade do grupo de trabalho. }\end{array}$ & $\begin{array}{l}\frac{\text { Hubpages }}{\text { Wikia }} \\
\frac{\text { Vyew }}{\text { 37signals }}\end{array}$ \\
\hline $\begin{array}{l}\text { Replicar software de } \\
\text { estilo de escritório } \\
\text { no navegador }\end{array}$ & $\begin{array}{l}\text { Aplicações de desktop/ferramentas de documentos } \\
\text { baseadas na web. Replicar aplicativos desktop. Com base em } \\
\text { desenvolvimentos tecnológicos. }\end{array}$ & Google tour \\
\hline $\begin{array}{l}\text { Ideias de origem } \\
\text { ou trabalho da } \\
\text { multidão }\end{array}$ & $\begin{array}{l}\text { Procure ideias e soluções para problemas ou obtenha tarefas } \\
\text { concluídas pela terceirização de usuários da web. }\end{array}$ & $\begin{array}{l}\text { Mturk } \\
\underline{\text { Innocentive }}\end{array}$ \\
\hline
\end{tabular}

Fonte: Traduzido e adaptado de Anderson (2007, p. 13).

O quadro 1 traz breve descrição e exemplos de serviços adequados as sete categorias gerais. Com este quadro é possível ter noções gerais da existência de diversos tipos de serviços classificados dentro do conceito de Web 2.0.

Enquanto na literatura revisada foram identificados diversos estudos que apresentam, listam e/ou descrevem os principais serviços 2.0, como em Anderson (2007), a literatura referente aos recursos 2.0 é bastante escassa. Não foi localizado nenhum trabalho que se propusesse a desenvolver o tema de forma tão ampla como acontece com os serviços. O que se tem são pesquisas específicas a determinados tipos de serviços que mencionam alguns recursos. Embora não tenham sido localizados estudos mais específicos sobre os recursos 2.0, observaram-se alguns fatos sobre o assunto. O fato mais importante visualizado foi que o processo de identificação dos recursos 2.0 tem sido algo muito subjetivo, é geralmente feito através de observação empírica em serviços 2.0, não há embasamento teórico para identificar recursos. Por exemplo, um serviço de marcação social como o delicious disponibiliza recursos para etiquetar (tag) favoritos e compartilhar com outros usuários. Assim entende-se o recurso de etiquetagem como um recurso 2.0. Outro exemplo, um serviço de rede social como o Facebook deverá ter alguns recursos 2.0 como, recursos para curtir, comentar, compartilhar. No caso dos blogs, que são uma espécie de diários eletrônicos, é possível que os usuários visitantes deixem comentários e estabeleçam discussões com os autores do próprio serviço ou entre os demais associados. Considerando a definição de blogs de Anderson (2007) como simples páginas constituídas por breves parágrafos de opinião, poderia se entender que os recursos disponíveis para os usuários comentarem e estabelecerem 
discussão são recursos adicionais, pois bastaria a um $b \log$ apenas disponibilizar seus parágrafos de opinião organizados de forma cronológica para ser classificado como tal. Lembrando que os recursos de comentar, avaliar, curtir, compartilhar podem ser observados em diversos tipos de serviços. Desse modo, é possível inferir que os serviços classificados como 2.0 devem possuir recursos também 2.0 e que estes podem ser aplicados a outros tipos de serviço.

Se o conceito chave de Web 2.0 é "interação", como proposto por Anderson (2007), Funk (2007) e O’Reilly (2005), convém considerar que serviços e recursos 2.0 são aqueles que, de alguma forma, permitam, facilitem, promovam o estabelecimento de relações interativas nesse ambiente. Diante do exposto é possível observar que alguns recursos vão sendo absorvidos por outros tipos de serviços, por exemplo, atualmente lojas eletrônicas disponibilizam recursos 2.0, como curtir, comentar, compartilhar e avaliar para os usuários/clientes. Neste caso, é possível perceber que vários tipos de serviço que, de algum modo, pretendam se inserir no conceito Web 2.0 vão buscando copiar e absorver recursos 2.0 populares entre os usuários da Internet. É o caso do objeto de estudo deste artigo (os catálogos bibliográficos) que percorreria o mesmo caminho para se tornar um serviço 2.0 (OPAC 2.0).

\subsection{A controvérsia da WEB 2.0}

No processo de revisão bibliográfica sobre as propriedades da Web 2.0 foram também identificadas publicações de especializadas com críticas desfavoráveis ao tema, como Carr (2005), Dvorak (2006) e o próprio criador da Web, Tim Berners-Lee apud Anderson (2006). Todos estes autores discordam sobre o que se entende por Web 2.0. O principal motivo para tais críticas, de modo geral, seria a inexistência de uma ruptura do modelo, já que mecanismos classificados como Web 2.0 já eram identificados na suposta Web 1.0. Para alguns críticos, a Web 2.0 é apenas uma jogada de marketing observada após a crise ocorrida nesse setor e que recursos ditos "Web 2.0" podem ser facilmente identificados em uso há muito tempo. Basicamente, não seria possível falar em Web 2.0, pois não houve mudança no modelo da web, o que houve teria sido somente um aperfeiçoamento tecnológico.
Para Carr (2005) a ideia de Web 2.0 é aceitável, porém este autor enfatiza os aspectos negativos considerando o lado amoral da suposta nova geração da web. De acordo com Carr (2005) é preciso fazer uma análise mais ponderada sobre a Web 2.0, pois se por um lado a mesma trouxe novas possibilidades de interação e cooperação, por outro, deu muita liberdade ao amadorismo, consequentemente, contribuiu para possibilidade de reduzir a qualidade e a confiabilidade nesse ambiente.

Tim Berners-Lee, idealizador da World Wide Web, discorda da ideia de Web 2.0:

\begin{abstract}
Absolutamente não! Web 1.0 tinha tudo a ver com conexão de pessoas. Ela foi um espaço interativo, e eu penso que Web 2.0 é de fato um jargão, ninguém realmente sabe o que significa. (BERNERS-LEE apud ANDERSON, 2006, online, tradução nossa).
\end{abstract}

Dvorak (2006), colunista especialista em tecnologia norte-americano alega que não faz sentido a ideia de Web 2.0, pois a web continua sendo a mesma, houve apenas uma simples evolução.

\begin{abstract}
A Web 2.0 é o último apelido em um esforço interminável para reativar a mania ponto-com do final dos anos 90. Este parece estar sendo bemsucedida. O problema é que pouco mudou. As más ideias do passado foram renomeadas e renovadas. (DVORAK, 2006, online, tradução nossa).
\end{abstract}

Considera-se importante ter ciência destes aspectos contraditórios sobre a Web 2.0, pois o OPAC 2.0 pode enfrentar as mesmas críticas. Por exemplo, seria bem possível identificar características supostamente exclusivas de OPAC 2.0 em catálogos eletrônicos de gerações passadas. Já a ideia de que recursos da Web 2.0 trazem problemas, como argumenta Carr (2005) é mais importante por revelar a necessidade de ter cautela ao propor a adesão a recursos Web 2.0 sem as devidas reflexões.

\section{WEB 2.0 E CIÊNCIA DA INFORMAÇÃO}

A revisão de literatura revelou a existência de pesquisas na área de CI a respeito da Web 2.0. 
Em grande parte dos estudos revisados, como em Gregory (2014), Barsky e Purdon (2006), Harinarayana e Vasantha Raju (2010), observou-se a tentativa de aperfeiçoar atividades e serviços de informação alinhando-os as tendências de tecnologias e Web 2.0.

Silva (2013) pesquisou métodos de indexação colaborativa como a folksonomia e catálogos facetados. Na pesquisa foram analisadas algumas ferramentas da Web 2.0 como wikis, a própria Wikipédia e sistemas de votação como o do YouTube. O estudo de Silva (2013) se aproxima dos princípios da "inteligência coletiva" e da "importância dos dados" (dados são o novo Intel Inside) propostos por O'Reilly (2005), para se referir ao estímulo dado pelos administradores dos sites aos usuários para que produzam informações. Silva (2013) observa que esse o estímulo à interação e colaboração proporcionam mais visibilidade e melhorias nos serviços.

Ainda relacionado à atividade de indexação, Barroso e Villalobos (2012) lembra que todo o processamento técnico do acervo nas bibliotecas brasileiras é realizado internamente pelos bibliotecários e que os catálogos, produto deste trabalho, são tradicionalmente fechados e não possibilitam que usuários das bibliotecas universitárias façam a inclusão de dados diferente daqueles já previstos.

A biblioteca como serviço também tem sido alvo de proposta se adaptar ao modelo Web 2.0 através da "Biblioteca 2.0", termo inicialmente cunhando por Michael Casey (Maness, 2007). Para Casey (2006) a biblioteca 2.0 é a mudança de orientação do serviço centrado no usuário de tal modo que incentiva a mudança constante e proposital, convidando a participação do usuário na criação dos serviços físicos e virtuais desejados. Segundo Lima (2011) o conceito de Biblioteca 2.0 está associado ao modo como a Web 2.0 provocou mudanças nas formas como as bibliotecas oferecem acesso às suas coleções e no modo em que interagem com o usuário. Para Seoane García (2016) através das tecnologias e aplicações Web 2.0 seria possível que as bibliotecas redesenhassem seus serviços. A autora lista algumas das aplicações e serviços esperados na Biblioteca 2.0, como:
- Serviços 24/7: referência virtual, mensagens instantâneas;
- $\quad$ Acesso remoto à informação, em qualquer lugar e a qualquer momento;
- Integração social;

- $\quad$ Centros locais de informação;

- Abordar as demandas e necessidades de novos usuários, especialmente os nativos digitais;

- Dar visibilidade à biblioteca e divulgar nossos serviços e produtos;

- Continuar a ser relevante e as organizações de referência ao falar sobre serviços de informação.

Em uma análise atenta a essa proposta, observa-se que muito do que foi listado já é aplicado por muitas bibliotecas. Lima (2011) mencionou algumas aplicações que já foram mencionadas nesse artigo, como mensagens instantâneas, vídeo e áudio, blogs, wikis, redes sociais, etiquetagem, marcação social, sindicação/agregação de conteúdos e mashups.

\section{I WEB 2.0 e catálogos: o surgimento do OPAC 2.0}

Buscando a modernização dos catálogos de bibliotecas Tam, Cox e Bussey (2009) com o denominado "next-generation OPAC" (OPAC de próxima geração) desenvolveram um estudo de usuários para verificar a aceitação de novos recursos de interface e interatividade. Tam, Cox e Bussey (2009) mencionaram uma série de recursos esperados nesse tipo de catálogo, como: navegação facetada; ranking de relevância; caixa de texto simples; verificador simples; jaqueta de livros; tabela de conteúdo/resumos; comentários e classificações; Rss feeds; sugestões de empréstimo; nuvem de tag. Importante observar que Tam, Cox e Bussey (2009, p. 372, tradução nossa) categorizaram os recursos de duas formas distintas, como de "next-generation OPAC" ou como de "Web 2.0":

\footnotetext{
navegador facetado, a nuvem de tags, as sugestões de empréstimos e o ranking de relevância são os recursos mais desejáveis e úteis da perspectiva dos estudantes internacionais. Geralmente, os resultados deste estudo são consistentes com os resultados dos poucos estudos prévios, ou seja, os usuários gostam de recursos que podem melhorar a sua experiência de pesquisa, tais como classificação de relevância e sugestões de empréstimos, e não gostam de recursos antipatizantes com a Web 2.0, como feeds RSS, avaliações de usuários e avaliações.
} 
Os resultados da pesquisa de Tam, Cox e Bussey (2009) indica que os usuários não demonstraram grande interesse na adição de recursos Web 2.0, porém os autores da pesquisa não deixaram muito claro como foi feita a classificação das duas categorias de recursos (recursos de interface e recursos de Web 2.0).

Osborne e Cox (2014) acrescentam outros recursos para o "next-generation OPAC": Recursos de pesquisa simples e avançados, incluindo conteúdo integrado; Navegação facetada; Marcação (etiquetagem ou tag); Avaliação e revisões; E-shelf (prateleira eletrônica); Aparência visual e acessibilidade dos recursos. Para Osborne e Cox (2014, p. 39, tradução nossa), "em particular, os usuários acham os catálogos mais fáceis de usar devido aos recursos de próxima geração, que oferecem vários métodos para encontrar uma variedade de recursos a partir de uma única interface". O resultado da pesquisa de Osborne e Cox (2014) apresentou resultado semelhante ao de Tam, Cox e Bussey (2009), segundo o qual foi afirmado que os usuários não têm tanto interesse em recursos da Web 2.0. De acordo com os resultados obtidos por Osborne e Cox (2014), os usuários preferem "as opções de busca e navegação, em vez dos recursos da Web 2.0, embora tenha sido reivindicado que os usuários esperam e estão acostumados a usar ferramentas de rede social." (OSBORNE; COX, 2014 , p. 39). Em outras palavras, não é porque os usuários estão acostumados com ferramentas de redes sociais, ou dos recursos Web 2.0 que eles têm desejo desse mesmo tipo de mecanismo em OPAC bibliográficos.

Mais recente e mais específico ao caso da Web 2.0, Ribeiro e Silva (2015) propuseram o "catálogo bibliográfico 2.0", que seria basicamente a adaptação dos tradicionais catálogos de bibliotecas, ou catálogos bibliográficos, ao conceito Web 2.0. De acordo com Ribeiro e Silva (2015), o catálogo bibliográfico 2.0 se justifica pelo fato dos novos usuários estarem habituados ao ambiente da Web 2.0. Por este motivo, os usuários passaram a observar uma discrepância entre os serviços considerados Web 2.0 e os catálogos de bibliotecas, considerando o último obsoleto. Para Ribeiro e Silva (2015), o catálogo bibliográfico 2.0 possuiria algumas funcionalidades, como:

- $\quad$ Navegação hipertextual;

- Tags provenientes de campos como título, autor, descrição física, palavras-chave;
- Informações importantes destacadas por fontes com tamanhos e cores diferenciadas;

- Recomendação de itens disponíveis no acervo;

- $\quad$ Avaliação de obras mediante a inserção de estrelas;

- Dados integrados aos repositórios institucionais, bases de dados, editoras e fontes externas;

- $\quad$ Sistema de tags (representação temática).

Após a apresentação de um modelo protótipo de um OPAC 2.0 Ribeiro e Silva (2015) chegaram a seguinte conclusão sobre a ferramenta:

Conclui-se que o catálogo bibliográfico 2.0 apresenta um ambiente dinâmico e intuitivo que permite e incentiva a participação ativa dos usuários mediante avaliação dos registros, sugestão de livros cujos gêneros sejam similares e rotulação livre, diferentemente das propostas dos tradicionais OPAC, sem participação do usuário, dificuldades na navegação e insatisfação nos processos de busca. (RIBEIRO; SILVA, 20I5, p. I8).

Vieira e Baptista (2010), no ENANCIB de 2010, apresentaram um estudo que investigou a questão da interação dos usuários de softwares sociais encontrados na Internet com relação ao que se deve esperar de um catálogo on-line de bibliotecas que utilize tais recursos interativos, ou seja, recursos 2.0. Estes autores optaram pela utilização da expressão "Social OPAC" como a união do tradicional OPAC com a "adoção dos aplicativos sociais da Web 2.0". (VIEIRA; BAPTISTA, 2010, p. 4). A análise no estudo de Vieira e Baptista (2010) foi desenvolvida com base em OPAC 2.0 encontrados no mercado seguindo critérios de usabilidade, funcionalidade e estruturação da informação. Foram citados como exemplos de Social OPAC, o Encore da Universidad Complutense de Madri, LibraryThing (norte americano) Hennepin County Library (norte americano). Vieira e Baptista (2010) concluíram, à época, que os Social OPAC ainda não eram adotados no Brasil e que as bibliotecas que usam softwares nacionais poderiam cobrar dos seus fornecedores que tais funcionalidades fossem inseridas. Para Webb e Nero (2009) existe a opção dos OPAC 2.0 serem fornecidos por uma empresa ou criados por sua própria instituição. 
Ainda sobre o OPAC 2.0, Lima (2011) sintetizou o termo de forma bem simples: "A expressão OPAC 2.0 refere-se aos catálogos Online com funcionalidades da Web 2.0". Como já mencionando, Lima (2011) parte de estudos que consideram a possibilidade de bibliotecas estarem alinhada com o conceito de Web 2.0, sendo o catálogo apenas um dos elementos que comporiam a suposta Biblioteca 2.0. Em se tratando do OPAC 2.0, Lima (2011) apresentou em sua pesquisa uma lista (quadro 2) com várias funcionalidades:

Quadro 2: Funcionalidades esperadas em OPAC 2.0

\section{Funcionalidades do OPAC 2.0}

Incluir ferramenta do tipo "Quis dizer?" para detectar possíveis erros ortográficos do usuário;

Estabelecer sistemas de ordenação de resultados que combinem metadados e informação social;

Enriquecer os registros bibliográficos com a capa do livro, o sumário, índices, etc.;

Contextualizar o autor;

Criar feeds RSS predefinidos e personalizados;

Possibilitar hiperligações a outros recursos de informação;

Criar acesso ao catálogo via WAP (Wireless Application Protocol) para usuários de telefones móveis ou

Personal digital assistants - PDA (computadores de mão);

Permitir que os usuários incluam etiquetas, avaliações e comentários aos registros bibliográficos;

Permitir que selecionem documentos como favoritos, que os organizem em pastas e compartilhem;

Incluir ferramentas de redes sociais;

Permitir uma pesquisa personalizada, segundo os seus favoritos, etiquetas ou requisições;

Mostrar um ranking de livros muito requisitados;

Mostrar livros relacionados, através de um sistema de recomendações;

Manter um perfil para cada utilizador que possa ser compartilhado;

Permitir a criação de um avatar;

Possibilitar a criação de grupos de usuários, fóruns de discussão e chats; etc.

Fonte: Traduzido e adaptado de Lima (2011, p. 25).

De acordo com Lima (2011) existem várias bibliotecas que implementaram essas ferramentas e empresas fornecedoras de OPAC que oferecem esses tipos de recursos. O WorldCat da Online Computer Library Center (OCLC) foi citado na pesquisa como um OPAC 2.0.

\section{RESULTADOS E DISCUSSÃO}

De acordo com a revisão de literatura, pôde-se verificar como resultado a identificação e o esclarecimento de princípios, serviços e recursos da Web 2.0. Também foi possível verificar como surgiu a ideia de se desenvolver um OPAC 2.0, bem como sugestões de recursos para esse tipo de instrumento que funcionaria como um serviço 2.0.
Em uma primeira análise, convém considerar que o a Web 2.0 possui princípios, portanto, estes devem ser observados em serviços que reivindiquem serem classificados como um produto ou serviço Web 2.0. Desse modo, para um OPAC ser classificado com 2.0, convém verificar se este atende aos princípios mencionados. Nesse ponto, há que se mencionar como problema observado que o alinhamento dos OPAC com princípios da Web 2.0 tem sido esquecido nas discussões sobre o assunto. A impressão que fica é que o OPAC 2.0 depende somente da inserção de recursos 2.0 que por si só serão o suficiente para modernizar os catálogos atendendo a demanda dos usuários.

Sobre o OPAC 2.0 verificou-se, ainda, que esta proposta consiste em alinhar o OPAC 
tradicional com a Web 2.0. Observou-se que o empreendimento em pesquisas e esforços em adaptar o OPAC dentro da ideia de Web 2.0 ocorreu por uma suposta demanda do usuário, a qual seria atendida uma vez que os OPAC oferecessem recursos 2.0. O fato observado é que tudo se inicia com uma demanda por serviços mais modernos, para Lima (2011), assim como para Ribeiro e Silva (2015), existe um novo perfil de usuários de sistemas de informação. Trata-se de uma nova geração de usuários que desenvolveram competências e necessidades informacionais diferentes de gerações anteriores. "Uma geração que cresceu com os computadores pessoais, os jogos de vídeo e a Internet, entre outras tecnologias". (LIMA, 2011, p. 13, tradução nossa). Por este motivo, acredita-se que usuários habituados ao ambiente da Web 2.0 esperam por "sistemas mais simples e intuitivos, interface mais amigável, com resultados de pesquisas mais relevantes, auxílio automático de pesquisa, navegação por hiperlink". (LIMA, 2011, p. 14). Para Castro e Moreno (2013) o OPAC 2.0 se justifica pelo mesmo motivo, a "demanda do usuário":

Contudo, as bibliotecas vêm sofrendo
com as exigências impostas pelos
avanços tecnológicos e pelo novo
perfil de usuários. Influenciados pelo
desenvolvimento tecnológico, os
usuários do século XXI acabaram
desenvolvendo habilidades diferentes
de outras gerações de usuários que
os antecederam, são os chamados
nativos digitais, usuários familiarizados
com as novas tecnologias. (CASTRO;
MORENO, 20I3, p. 8).

Se de acordo com a revisão de literatura, o OPAC 2.0 não seria nada mais do que a combinação do velho e conhecido OPAC com a Web 2.0. Essa definição simples tem levado a crer que o caminho para o desenvolvimento do OPAC 2.0 é absorção de recursos típicos desse ambiente. Tais recursos são aqueles que possibilitam aos usuários terem uma experiência mais interativa com os sistemas acessados. Entretanto, o que parece simples se complica com a falta de clareza na definição do seriam os recursos de Web 2.0. Se o OPAC 2.0 é aquele que absorve recursos 2.0, um fato observado, e bastante problemático, foi que em todas as pesquisas revisadas os recursos sugeridos carecem de fundamentação científica ou técnicas, pois não foi encontrado nos estudos nenhum método explícito para identificar ou classificar recurso Web 2.0. Nesse sentido foi observado como prática comum a apresentação de recursos sem maiores explicações do seu funcionamento ou do motivo para classificá-los como tal. Na seção anterior, por exemplo, foram apresentados vários recursos, hora recursos de "catálogos de próxima geração" que se misturam e confundem com recursos de Web 2.0, recursos de "catálogos bibliográficos 2.0", e, inclusive, uma lista elaborada por Lima (2011) contendo 16 recursos para OPAC 2.0. Porém, nem mesmo no estudo específico de OPAC 2.0 de Lima (2011) foram observadas maiores explicações do método de identificação desses recursos. O mais provável é que os recursos mencionados são identificados de forma empírica sendo aplicados a serviços típicos de Web 2.0, como redes sociais, blogs, wikis e comércio eletrônico. Nesse caso, talvez fosse importante considerar pelo menos os sete princípios da Web 2.0 para identificar e classificar os recursos desse ambiente.

A ideia de se adicionar recursos $2.0 \mathrm{em}$ OPAC porque há uma suposta demanda por parte de usuários de nova geração parece ser o caminho mais lógico para construir o OPAC 2.0, entretanto, pode ser bastante contraditória em alguns casos. Conforme já exposto, de acordo com as conclusões das pesquisas de opinião de usuário realizadas por Tam, Cox e Bussey (2009) e Osborne e Cox (2014), os usuários não demonstraram grande interesse em recursos da Web 2.0 em catálogos bibliográficos. Além disso, de acordo com as conclusões de Lima (2011), que realizou um estudo com bibliotecários universitários sobre o desejo de implementação de alguns recursos, a autora afirma que "as ferramentas sociais foram consideradas como as menos importantes de aparecer num OPAC (etiquetas, comentários, criação de grupos de usuários com interesses semelhantes, redes sociais, fóruns de discussão e chats, ranking de livros e sugestões)". (LIMA, 2011, p. 48 , tradução nossa).

Como visto, o resultado da tentativa de modernizar catálogos de bibliotecas adicionando recursos, tecnologias, funcionalidades, serviços e/ ou aplicações Web 2.0, como se pôde observar, tem sido denominado de maneiras distintas, e às vezes ambígua, conforme exposto na seção anterior. $\mathrm{Na}$ revisão de literatura, foram identificadas, por exemplo, as expressões "OPAC 2.0", "Social OPAC", "next-generation OPAC" e "catálogo 
bibliográfico 2.0". Enquanto que as formas de denominar os novos catálogos foram diversas, pelo menos foi possível observar um ponto em comum a todos os estudos revisados: a tentativa de aproximação com a Web 2.0. Desse modo, entende que se houve, ou se ainda há, a tentativa de adequar os catálogos online de bibliotecas ao conceito Web 2.0, ou seja, torná-lo um serviço Web 2.0, esse serviço então precisaria absorver recursos Web 2.0. A documentação revisada revela a menção e, algumas vezes, sugestão de diversos recursos para o suposto OPAC 2.0. Assim, conforme o discutido foi possível compreender como que a Web 2.0 foi se aproximando dos catálogos e como surgiu a ideia de se desenvolver o "OPAC 2.0 ".

\section{CONSIDERAÇÕES FINAIS}

Pode-se verificar que há por parte da comunidade científica da área de CI um esforço para modernizar os catálogos de bibliotecas, e um dos caminhos propostos é a inserção dos OPAC na Web 2.0. Entretanto, ainda são necessários maiores esclarecimentos sobre as propriedades da Web 2.0 e dos recursos provenientes desse ambiente, a literatura especializada ainda carece de fundamentação teórica e procedimentos técnicos para identificação, classificação e avaliação de OPAC que venham a reivindicar o "selo" 2.0. A proposta do desenvolvimento de uma metodologia também faz parte do estudo que originou o presente estudo, porém não seria possível apresentá-lo neste pequeno artigo de revisão. Pelo visto, acredita-se que copiar recursos 2.0 de serviços populares entre os usuários de nova geração seja o caminho para construir o OPAC 2.0. Todavia, verifica-se que sem as devidas reflexões e esclarecimento, correse o risco de desenvolver serviços desalinhados com as reais necessidades dos usuários, conforme foi verificado no resultado de alguns estudos.

O objetivo proposto foi alcançado ao apresentar as propriedades da Web 2.0, como os sete princípios, exemplos de serviços e recursos 2.0 e OPAC 2.0. Este artigo é apenas uma pequena contribuição à tentativa de preenchimento de algumas lacunas observadas no tema. Entretanto é um passo adiante na formulação de maiores esclarecimentos e método de análise que visam subsidiar as tentativas de inserir os catálogos bibliográficos no conceito Web2.0.

Artigo recebido em 26/02/20। 8 e aceito para publicação em 20/04/20। 8

\section{OPAC 2.0: analyzing Web 2.0 properties, services, and features}

ABSTRACT In recent years, Online Public Access Catalogs (OPAC) have undergone transformations due to the technological development and a surprising requirement of users accustomed to more interactive services provided by Web 2.0. In an attempt to meet the user's wishes, observe in some studies the proposal for the development of OPAC 2.0. In this case, it should be noted that if OPAC 2.0 is what is around the Web 2.0 concept and makes use of its mechanisms, it is considered opportune to investigate through an exploratory study such as Web 2.0 principles, such as principles, services and resources that give rise to the proposed OPAC 2.0. This study therefore aims to provide greater clarity regarding the properties of Web 2.0 in relation to what is expected of an OPAC 2.0. For this task specialized literature was used to establish linkages between Web 2.0 and Information Science $(\mathrm{Cl})$ and to identify methods of evaluating, classifying or identifying elements of Web 2.0 in information services. The result of the research indicates that the specialized literature still lacks the theoretical foundation and technical procedures to evaluate OPAC that come to claim the "seal" 2.0. It is concluded that without the necessary reflections and clarification, there is a risk of developing services that are not in line with the real needs of users.

Keywords: $\quad$ OPAC 2.0. Web 2.0. Features 2.0. Catalogues.

Inf. \& Soc.:Est., João Pessoa, v.28, n.2, p. 21-36, maio/ago. 2018 


\section{REFERÊNCIAS}

ANDERSON, Nate. Tim Berners-Lee on Web 2.0: "nobody even knows what it means". 2006. Disponível em: <http://arstechnica.com/news. ars/post/20060901-7650.html>. Acesso em: 16 maio 2017.

ANDERSON, Paul. What is Web 2.0? ideas, technologies and implications for education. JISC Technology and Standards Watch. 2007. Disponível em: <http://www.ictliteracy.info/ rf.pdf/Web2.0_research.pdf $>$. Acesso em: 8 maio 2017.

BARROSO, Patrícia; VILLALOBOS, Ana Paula. OPAC social: tendências e desafios para as bibliotecas universitárias. In: I Encontro Nacional de Catalogação - ENACAT, 2012, Rio de Janeiro. Anais... 2012. Disponível em: <https:// repositorio.ufba.br/ri/bitstream/ri/14633/1/ trabalho\%20enacat\%20rj2012.doc.pdf>. Acesso em: 2 fev. 2017.

BARSKY, Eugene; PURDON, Michelle. Introducing Web 2.0: social networking and social bookmarking for health librarians. Journal of the Canadian Health Libraries Association, [S.1.], v. 27, n. 3, p. 65-67, set. 2006. Disponível em: <https://journals.library.ualberta.ca/jchla/ index.php/jchla/article/view/22472>. Acesso em: 13 abr. 2018.

BEMBEM, Angela Halen Claro; SANTOS, Plácida Leopoldina Ventura Amorim da Costa. Inteligência coletiva: um olhar sobre a produção de Pierre Lévy. Perspect. ciênc. inf., [S.1.], v. 18, n. 4, p. 139-151, dez.2013. Disponível em: <http:// portaldeperiodicos.eci.ufmg.br/index.php/pci/ article/view/1639>. Acesso em: 3 jan. 2018.

BRAGA, E.C. As redes sociais e suas propriedades emergentes como a inteligência coletiva. A criação do comum e da subjetividade. Revista Digital de Tecnologias Cognitivas, São Paulo, n. 2, p. 48-59, jul./dez. 2009. Disponível em:<http://www.pucsp. br/po s/tidd/teccogs/artigos/pdf/tec cogs_ n2_2009_artigo_braga.pdf>. Acesso em: 5 abr. 2018.

CARR, Nicholas. The amorality of Web 2.0. [S.1.], 2005. Disponível em <http://www.roughtype. com/ ?p=110>. Acesso em: 27 maio 2017.
COELHO, Geovália Oliveira; ISHITANI, Lucila; NELSON, Maria Augusta Vieira. VITAE: recuperação de objetos de aprendizagem baseada na Web 2.0. ETD - Educ. temat. digit, Campinas, 2012, v. 14, n. 2, p. 238-257. jul./dez. 2012. Disponível em: <http://educa.fcc.org.br/pdf/ etd/v14n02/v14n02a15.pdf>. Acesso em: 5 abr. 2018.

CASEY, M. E; SAVASTINUK, L. C. Library 2.0: Service for the Next-Generation Library. Library Crunch. [S.1], online, jan. 2006. Disponível em: <https://docs.google.com/ file/d/0B6Rc1-COLCvreWJveVh6c0VCOWs / edit?usp=sharing >. Acesso em: 5 abr. 2018.

CASTRO, M. V; MORENO, F. P. Catálogo 2.0: um estudo de caso em bibliotecas universitárias do centro-oeste brasileiro. In: ENCONTRO INTERNACIONAL DE CATALOGADORES, 9, 2013, Rio de Janeiro. Anais... Rio de Janeiro: Fundação Biblioteca Nacional, 2013. Disponível em: <http://www.abinia.org/catalogadores/44227-1-PB.pdf>. Acesso em: 9 jan. 2018.

DVORAK, John C. Web 2.0 baloney. Disponível em: <www.pcmag.com/article2/0,2817,1931858,00. asp>. Acesso em: 3 jan. 2018.

FUNK, Tom. Web 2.0 and beyond: understanding the new online business models, trends, and technologies. Westport: Praeger Publishers, 2007. Disponível em: <https://samuelschmidt.wikispaces.com/file/ view / Livro+-+WEB+2.0+AND+BEYOND++Tom+Funk.pdf>. Acesso em: 8 maio 2017.

GARCÍA ARETIO, Lorenzo. Web 2.0 vs web 1.0. Didáctica, Innovación y Multimedia, Barcelona, v. 3, n. 10, p. 1-8. dez. 2007. Disponível em: <http://www.raco.cat/ index.php/DIM/article/view/76637>. Acesso em: 3 abr. 2018.

GREGORY, Gwen M. Library catalogs: the next generation. Information Today, Medford, v. 31, n. 2, p. 26, mar. 2014. Disponível em: < http:// search-ebscohost-com.ez27.periodicos. capes.gov.br/login.aspx? direct $=$ true $\& d b=a$ ph\&AN=94767023\&lang $=$ pt-br\&site $=$ ehost live\&authtype $=i p, c o o k i e, u i d>$. Acesso em: 13 abr. 2018. 
HARINARAYANA, N. S; VASANTHA RAJU, N. Web 2.0 features in university library web sites. The Electronic Library, [S.1.], v. 28, n. 1, p. 69-88, fev. 2010. Disponível em: <https://doi. org/10.1108/02640471011023388>. Acesso em: 13 abr. 2018.

HOSSAIN, Md. Mokter; AYDIN, Hasan. A Web 2.0-Based Collaborative Model for Multicultural Education. Multicultural Education \& Technology Journal, [S.1.], v. 5, n. 2, p. 116-128, 2011. Disponível em: <https://doi. org/10.1108/17504971111142655>. Acesso em: 10 abr. 2018

JOHNSON, Frances C.; CRAVEN, Jenny. The Study of Functionality of the 2.0 Online Catalogue. New Review of Academic Librarianship, Manchester, v. 16, n. 2, p. 228-250, nov. 2010. Disponível em: < http:// search-ebscohost-com.ez27.periodicos. capes.gov.br/login.aspx?direct $=$ true $\& d b=1$ ih \&AN=54594106\&lang $=$ pt-br\&site $=$ ehost live\&authtype $=i p, c o o k i e, u i d>$. Acesso em 14 abr. 2018.

LÉVY, P. A inteligência coletiva: por uma antropologia do ciberespaço. 4. ed. São Paulo: Loyola, 2003.

LIESEGANG, Thomas J. Web 2.0, Library 2.0, Physician Learning 2.0. Ophthalmology, [S.1.], v. 114, n. 10, p. 1801-1803, set. 2007. Disponível em: <https://doi.org/10.1016/j.ophtha.2007.07.038>. Acesso em: 5 abr. 2018.

LIMA, Sandra Carla Borges de. A inevitabilidade do OPAC 2.0. 2011. Dissertação (Mestrado em Informação, Comunicação e Novos Media) Faculdade de Letras da Universidade de Coimbra, Portugal, 2011. Disponível em: <https:// estudogeral.sib.uc.pt/bitstream/10316/18936/1/ Disserta \% C3\% A7\% C3\% A3o\%20_Sandra \% 20 Lima.pdf>. Acesso em: 3 fev. 2015.

MANESS, J. M. Library 2.0 Theory: Web 2.0 and Its Implications for Libraries. Webology, v. 3, n. 2, online, jun. 2006. Disponível em: http://www.webology. org/2006/v3n2/a25.html. Acesso em: 5 abr. 2018.

O'REILLY, Tim. What Is Web 2.0?: design patterns and business models for the next generation of software. 2005a. Disponível em: <http://www.oreilly.com/pub/a/web2/ archive/what-is-web-20.html>. Acesso em: 19 set. 2016.

\section{Web 2.0 Compact Definition:} Trying Again. 2006. Disponível em: <http:// radar.oreilly.com/2006/12/web-20-compactdefinition-tryi.html>. Acesso em: 7 jan. 2016.

OSBORNE, Hollie M.; COX, Andrew. An investigation into the perceptions of academic librarians and students towards next-generation OPACs and their features. Program: electronic library and information systems, v. 49, n. 1, p. 23-45, 2015. Disponível em: <https://doi. org/10.1108/PROG-10-2013-0055>. Acesso: 3 jan. 2017.

RIBEIRO, Danielly Santos; SILVA, Márcio Bezerra da. Sistema de Gerenciamento de Conteúdo: proposta de um catálogo bibliográfico 2.0 no Wordpress. RDBCI: Revista Digital de Biblioteconomia e Ciência da Informação, Campinas, SP, v. 14, n. 1, p. 144-163, dez. 2015. Disponível em: <https://periodicos.sbu. unicamp.br/ojs/index.php/rdbci/article/ view/8640820>. Acesso em: 6 nov. 2017.

SANTOS, H. N. Políticas culturais e inteligência coletiva. Contemporânea, Rio de Janeiro, v. 9, n. 1, p. 36-45, 2011. Disponível em: <http:// www.contemporanea.uerj.br/pdf/ed_17/ contemporanea_n17_03_nepomuceno.pdf $>$. Acesso em: 3 abr. 2018

SEOANE GARCÍA, Catuxa. La biblioteca 2.0: de la biblioteca expositiva a la biblioteca interactiva. In: ANTÓNIO CALIXTO, José (Dir.). Bibliotecas para a vida II: Bibliotecas e Leitura. Évora: Cidehus, 2016, online. Disponível em: <http:// books.openedition.org/cidehus/513>. Acesso em: 9 jan. 2017.

SILVA, Marcel Ferrante. Proposta de modelo de colaboração para catálogo web facetado. 2013. Tese (Doutorando em Ciência da Informação) Escola de Ciência da Informação, Universidade Federal de Minas Gerais, Belo Horizonte, 2013. Disponível em: <http://www.bibliotecadigital. ufmg.br/dspace/bitstream/handle/1843/BUOS9JLJJF/tese_doutorado_2013_marcel_ferrante_ 
silva_eci_ufmg.pdf?sequence=1>. Acesso em: 20 ago. 2015.

TAM, Winnie; COX, Andrew M.; BUSSEY, Andy. Student user preferences for features of nextgeneration OPACs: A case study of University of Sheffield international students, Program: electronic library and information systems, v. 43, n. 4, p. 349-374, 2009. Disponível em: <https:// doi.org/10.1108/00330330910998020>. Acesso em: 3 jan. 2017.

VIEIRA, D. V.; BAPTISTA, S. G. Uma análise do perfil de um Social OPAC presente na Biblioteca
2.0. In: ENCONTRO NACIONAL DE PESQUISA EM CIÊNCIA DA INFORMAÇÃO, 11, 2010, Rio de Janeiro. Anais eletrônicos... Rio de Janeiro: UFRJ, 2010. Disponível em: <http://enancib. ibict.br/index.php/enancib/xienancib/paper/ viewFile/3585/2708>. Acesso em: 5 set. 2015.

WEBB, Paula L.; NERO, Muriel D. OPACs in the clouds. Computers in Libraries, Medford, v. 29, n. 9, p. 18-22, out. 2009. Disponível em: <http://go-galegroup.ez27.periodicos.capes. gov.br/ps/i.do?\&id=GALE | A209239630\& $\mathrm{v}=2.1 \& \mathrm{u}=$ capes\&it $=$ $\mathrm{r} \& \mathrm{p}=\mathrm{AONE} \& \mathrm{sw}=\mathrm{w}>$. Acesso em: 10 abr. 2018. 